was both softened and covered with that thick, pulpy substance which is so often found about diseased joints. Moreover, there was ulceration of that part of the os calcis which comes into contact with the os cuboides.

I remember, many years ago, a case of fracture of the neck of the astragalus in a young man, who came to the ground on his feet from a great height. He was admitted into this hospital, under the care of Mr. Stanley; and the explanation of the character of the accident was, that in consequence of his being the subject of flat-foot the weight of the body was transmitted to the ground directly through the head and neck of the astragalus, which formed the lowest part of the sole of the foot.

In such a case the internal lateral ligament must have become elongated, so that the astragalus would not only sink to the ground, but lie also somewhat obliquely in the tarsus. Finally, the peronei muscles raise the outer border of the foot, the peroneus longus abducting the anterior half; the remaining muscles acting spasmodically, and keeping their respective tendons tense. The tendo-Achillis becomes also tight from spasm of the muscles of the calf, and does not permit the foot to be raised.

Now, when the tendo-Achillis is tight, and drags upon the posterior extremity of the os calcis, it is obvious that it offers a serious resistance to the raising of the arch of the foot. The os calcis does not, in its natural position, lie quite horizontal; the heel only touches the ground, the anterior extremity being raised to a level with the articular border of the os scaphoides. You may be obliged, then, in some cases, to divide the tendoAchillis before the usual means will be found efficacious.

In the simpler cases relief may be afforded by a boot with raised sole and outside irons with straps. The boot should be made broad in the sole, an elastic pad being introduced under the inner leather to give support to the head of the astragalus and to sustain the antero-posterior arch. A strap passed from the outside iron over the inner ankle, prevents that part from projecting inwards. Direct the patient to wear this apparatus from the moment he rises from the bed; let him never bear upon his feet one moment without the support. If the pad hurts him he should lie down until the uneasiness has passed away. By perseverance he will soon find the advantages of the treatment. But the pad must not be too large. I have known instances in which the pressure was so great and the surgical supervision so imperfect, that a slough formed in the sole of the foot, rendering the patient's condition more distressing than ever. If there is decided and permanent contraction of the peronei muscles they must be divided, but I think this operation is often performed when it is not necessary. Let the patient lie quiet in bed for two or three days, and the surgeon will notice a remarkable subsidence of muscular spasm and tension of the surrounding tendons. Still the tendo-Achillis - ften requires division. I had under my care quite lately in St. Bartholomew's Hospital an errand-boy suffering from talipes valgus, which had not been improved either by appa. ratus or by the division of the peronei tendons. Finding after a week's rest that the patient could not by any means raise the feet beyond a right angle, $I$ advised the division and extension of the two Achilles tendons. The operation was performed, and the case then proceeded favourably. But some months passed before he could walk about with strength and activity.

I must warn you not to confound "weak ankles" with "flat-foot." You see many weakly girls walking about with unsightly projection of the inner ankle, and it does not follow that in these cases the arch of the foot is lost. The point is easily ascertained by examination. In such cases no more would be required than an outside iron attached to the boot, with free movement at the ankle-joint, and the usual strap to pass round the lower part of the leg. But even this measure is not always necessary.

There is yet another and allied deformity of the foot, of which I must say a few words-namely, talipes equino-valgus. You have here in all cases contraction of the gastrocnemius muscle, combined with and proceeding from paralysis of the anterior and sometimes posterior tibial muscles, caused by irritation or disease of the nervous centres, difficult dentition being amongst the young one of the most commonest precursors. The heel is seldom raised beyond a right angle; the peronei and the extensor muscles are contracted; the front part of the foot is everted, the patient walking on the inner margin, and especially on the ball of the great toe, producing a great and constant strain on the internal lateral ligament, which is at times so weakened and elongated as to allow the astragalus to sink. I have examined cases after death, in which both the anterior and posterior tibial muscles have undergone an extreme degree of fatty degeneration, and you may possibly meet with similar specimens from time to time in the dissecting room.

In these cases, where the deformity is combined with paralysis, you can do no more than place the bones in their proper position, and give the patient artificial support. The contracted tendons must be divided; the abduction of the foot overcome by Scarpa's shoe. The foot must then be raised, and the padded boot and outside iron subsequently worn. By perseverance in such support, the ligaments will have time to recontract, when the limb may regain sufficient firmness to enable the patient to walk about with ease, and even for some hours in the day, with a common boot. But the other appliance must never be entirely laid aside, lest the deformity should return.

Such, gentlemen, is a brief outline of the deformities of the feet. You may observe that they are numerous, even under the simplest arrangement. In practice, however, you will find them more numerous still; but I have said, I hope, sufficient to show that he who chooses to become master of the subject, possesses the means of affording a vast amount of relief.

In my next lecture I shall proceed to the consideration of a subject on which, of late, much has been written-namely, the nature and treatment of curvatures of the vertebral column.

\section{REPORT OF A}

\section{CASE OF ANEURISM OF THE AORTA.} WITH REMARKS.

By PETER EADE, M.D., M.R.C.P., PHYSICIAN TO TEE NORFOLI AND FOBWICH HOSPITAL, ETC.

Double aneurismal sac; compressed bronchus and cesophagus; stretched and flattened pneumogastric nerve; destructive inflammation of lung; fatty heart.

THE subject of this case was a stout, fat man, fifty-two years of age, by trade a miller, who (with the exception of a slight attack of delirium tremens after a protracted debauch some seven or eight years ago) had always enjoyed excellent health until the commencement of his present illness. About tive months previous to his admission into the Norfolk and Norwich Hospital he began to suffer from cough, mucous expecto. ration, hoarseness, and wheezing respiration. These symptoms (which he attributed to cold) continued gradually to increase; and in March, 1860, when he first came under my observation, he presented all the appearances of a man suffering from subacute bronchitis.

At this time his breathing was loud, wheezing, and almost asthmatic in character, with occasional paroxysms of more urgent dyspncea. The expectoration consisted of a large quantity of serous fluid, mixed with a little bronchial mucus. On examining the chest, wheezing respiration with abundance of ronchous and sibilant rîles were heard, all these signs being much louder and more marked on the right than on the left side. The heart's sounds were weak and clear, but free from bruit. No abnormal murmur could be heard anywhere in the chest, nor any secondary centre of pulsation be made out; but there was distinct dulness on percussion in the middle of the left side of the chest. There was no inequality of the radial pulses, no sign of ossification of the arteries, and no contraction of either pupil. He stated that he was not conscious of having injured himself in any way, and that he had never spat blood.

A week later (April 3rd) his symptoms had become much aggravated. His breath was shorter, and the respiration more noisy-often almost stridulous, the cough and expectoration being equally troublesome. He now complained of pain in the left side of the chest and in the left scapular region, with occa. sional pains in the left shoulder and down the left arm. Distinct, but neither forcible nor extended, pulsation could now be felt beneath the upper part of the sternum, but no bruit (either now or at any subsequent period) could be satisfactorily made out. Percussion-dulness was now well marked in the left supra-mammary region and over the root of the left lung behind. The respiratory murmur on the right side was loud, noisily wheezing, and accompanied with loud moist and dry râles; whilst on the left side behind it was very feeble, and in front nearly absent over almost the entire lung. The 
left jugular vein had become much more distended than the right.

At my visit on April 7th, I found him just recovering from a severe attack of spasmodic dyspncea, with relaxed muscles, perspiring skin, livid countenance, and great respiratory labour and distress.

April 10th. - He had now somewhat improved as to his general condition, but the pulse and impulse of the heart were very soft and weak. The secondary pulsation had become more distinct and diffused, and could plainly be felt in the sternal notch, and beneath the inner end of the left clavicle.

16th. - He began to complain of difficulty in swallowing solid food.

24th. - He observed a little blood to have passed per anum.

29 th. - $\mathrm{He}$ is reported to have conghed up a little blood on each of the two or three preceding days.

May 1st. - The difficulty of breathing and of swallowing had increased. The cough, expectoration, hoarseness, and occa sional attacks of spasmodic dyspnex remained as before, and he complained much of pain in the left side. There was no increase of the area or force of the pulsating swelling.

Between this date and the 15th he continued gradually to fail in strength, his power of swallowing becoming at last limited to the taking of fluids. Twice or thrice during this fortnight he coughed up a considerable quantity of red frothy blood, and on the evening of this day he suddenly brought up a large quantity of nearly pure scarlet blood, and died in about a quarter of an hour afterwards.

The treatment adopted consisted at first of nitre, ipecacuanha, \&c., given with a view to checik the bronchitis, which was then the urgent symptom; but he was so much depressed by these remedies that stimulant expectorants-senega, squills, and ether, with opium - were obliged to be substituted, and from these he experienced decided relief. Subsequently, when the tumour was found to be increasing, ice to the chest, and acetate of lead internally, were had recourse to; but these, as well as every other depressant that was tried during the time he was in the hospital, were so markedly iujurious, that they. were compelled to be relinquished, and stimulants, with wine or brandy and good diet, to be given in their stead. Stimulants never appeared to excite the circulation or to increase the force of the pulsations, but, on the contrary, always seemed to make him quieter and more comfortable. He derived great relief from morphia and other preparations of opium, which were administered freely.

Body examined forty hours after death.-On raising the sternum, a tumour was seen beneath its upper part, which adhered to this bone and to the left upper ribs. The left external jugular vein was involved in it, and its cavity obliterated. The trachea was seen to be pushed over tô the right of the median line. From one to two pints of clear yellowish serum were found in the left pleural sac. The right lung was enormously distended; its lobules very plainly marked out on its surface, crepitant everywhere, and, when eut into, quickly collapsing. The left lung was collapsed, solid, and infiltrated throughout with dirty-white or greyish purulent matter, and with ly mph not yet converted into pus. Blood was found in the mouth and pharynx, but not in the trachea. On opening this tabe, the cartilages of the larynx were found to be rigid and ossified. The left bronchus was fiattened and compressed, but not quite closed, and about half an inch above its orifice in the wall of the trachea was seen an irregularly rounded, nlcerated opening, the size of the end of the little finger, which opening was found to communicate with the cavity of an aneurismal sac, through a mass of congulated fibrine contained in its interior. The œsophagus in its upper part was empty. Just below its middle it was encroached upon by a bulging swelling, of the size of a small orange, and just below this again was contracted to a very small size, but healthy. Coagulated blood was found in it both above and below the swelling. The heart was covered with much fat externally. Its walls were thin, and all its cavities enlarged. The muscular tissue of both right and left ventricles was found (under the microscope) to be in a state of advanced fatty degeneration; the valves were healthy. The aorta was greatly diseased; its lining membrane closely studded with atheromatons and bony scales and plates. These patches covered the greater part of its inner surface near the heart, and were very numerous and distinct even into its abdominal portion; but the large arteries of the neck, up to their junction with the aorta, were entirely free from disease. Two aneurismal sacs were found to spring from the aortal arch. One, the smaller, about the size of a duck's egg, sprang from its upper part, between (but not involving) the great arteries. It appeared to be composed of all the arterial tunics, was half filled with fibrinous coagulum, and communicated with the artery by an aperture so large as virtmilly to make it a portion of this tube. The other, the larger, also a true aneurism, and also opening into the aorta by an orifice nearly as large as the entire diameter of the sac, arose from the back part of the arch immediately behind the left subclavian artery. It formed the large bulging seen in the osophagus, and through the layers of fibrine contained in its interior blood had escaped by the ulcerated opening into the trachea. The left pneumogastric nerve was seen crossing over the front of the aorta to enter the left lung. It was much flattened (and must have been considerably stretched), and one large branch, just prior to its entrance into the lung, so much so as to exhibit quite an acute edge.

Remarks. - I do not now propose to make any observations upon the more common phenomena of aneurism presented by this case, but it does appear to me that it affords such an assemblage of some of the rarer features of the disease, and to. corroborate so strongly views lately put forth by some of the ablest observers in the profession, that I think it well worthy of a few passing comments.

The points which I wish particularly to notice are the fol. lowing:- -

1st. The existence of two distinct aneurismal sacs, both of which were true aneurisms, both apparently of about the same age, taking different directions, making pressure upon different organs (indeed the visible pulsating tumour in the neck was neither the cause of the dysphagia nor of the fatal issue), communicating with the aortal canal by large orifices, and both (probably for this latter reason) running their course without the development of any abnormal murmurs. From my own experience of this disease, and from the mode in which this subject is treated by authors, I apprehend that, though simple dilatations of the diseased aorta are not uncommon, and though an aneurism is not unfrequently present in more than one limb at the same time, yet the coexistence of more than one distinct ancurismal sac in the arch of the aorta is very rare.

2nd. The occurrence of hæmoptysis in cases of aneurism. Many cases are on record in which blood was expectorated by aneurismal patients weeks or months before the fatal result occurred. It is well known that in the case of the late Mr. Liston hæmoptysis took place to the extent of many ounces at least five months before his death; and Dr. Gairdner, in a communication to the Medico. Chirurgical Society last year, directed the attention of the profession to a remarkable case which had fallen under his observation, in which the first gush of blood had occurred four years and eight months before the patient's death, blood being also expectorated in varying times and quantities during the whole of this long period. Still these are the exceptions; and the general feeling and expectation is, that when rupture of the aneurism has once taken place the death of the patient from hrmorrhage is at hand. In the present case, about three weeks elapsed between the first observation of blood in the stools and the final fatal bæmorrhage.

3rd. Another point of great interest (indeed, the one which has induced me to place the case on record) is the illustration which we have here of the effect of interruption of the nervous supply on the nutrition of the great organs of the body. The autopsy showed the left pneumogastric nerve to be stretched and flattened, and the left lung in a state of destructive in. flammation. The connexion between these two conditions cannot, I think, be for a moment doubtful. The general expe. rience of the profession show's how prone parts whose nervous supply is only diminished are to run into inflammation of an asthenic character; and we all know how the nates slough in disease of the spinal cord; how the bladder inflames under the same circumstances; how a low form of inflammation occurs in the lungs of lunatics; how disease of the fifth nerve within the skull has been known to give rise to inflammatory destruction of the eyeball; and how experiment has shown that artificial division of the sympathetic and fifth nerves will give rise to a similar destruction of the eye. Dr. Reid's experiments on the artificial production of suppurative and gangrenous inflammation of the lung by division of the vagi nerves in dogs are also well known. Within the last two years, several illustrations of this effect of involvement of the nerves in other diseases lave been published. Thus,

Dr. Budd ("Medico-Chirurgical Transactions," 1859) alludes to cases in which suppurative inflammation of the gall-bladder arose from the cutting off of its nervous supply by cancerous disease of the liver; and gives in detail others in which suppu. ration of the lung followed engagement of the pulmonary plexus in thoracic cancer.

Dr. Gall ("Guy's Hospital Reports," 1859) reports three 
cases, one of aneurismal, and two of cancerous, disease of the chest, involving the pneumogastric nerve, in which destructive inflammation of the lung was found to have ensued.

Again, in the beginning of the past year, Dr. Fuller bronght before the Pathological Society a case (recorded in vol. Xi. of its "Transactions") very similar to the present, in so far as the lung on the side of the aneurism was in a state of suppurative inflammation. Here the tumour "adhered closely to, and pressed upon, the left lung, the greater part of the upper lobe of which was in a state of gangrene."

This point of pathology, then, may now be considered to be fully recognised and understood; but that it is only quite lately that this has been the case is shown by the fact, that so recently as 1855, Dr. Todd gave a clinical lecture upon "Aneurism of the Aorta," in which he described a destructive inflammation of the lung, running into gangrene, accompanying a thoracic aneurism which had compressed the root of the lung, and which gangrene he ascribed to compression of the pulmonary vessels, without even alluding to the possibility of the nerves having been in any way concerned in its production.

$4 \mathrm{th}$. There was present very extensive atheromatons disease of the aorta, with fatty degeneration of the muscle of the heart; and throughout, though a stout and well-formed man, he exhibited a very marked debility. At no time did he derive benefit from sedative treatment; but, on the contrary, this always appeared to make him worse, whilst he as constantly expressed himself as feeling better in ali respects for generous diet and stimulants, with astringents. And, I would ask, does not the confessed origin of the disease, in so many instances, in that condition of system which is known by the name of the fatty diathesis, and which is essentially one of low power and deficient organization, add a further argument to those which both theory and experience have adduced in favour of treating this disease less and less often by depletion, by starvation, and depressin 7 remedies, which, whilst diminishing the coagulability of the llood, increase the irritability of the heart, and of treating it (where any interference seems de. sirable) more stearlily by moderate attempts to bring the sys tem into such a state that the fibrine shall be improved in coagulating power, the tone of the valls of the sac increased, so as better to resist the dilating strain put upon them, and the tendency of the albuminous tissues to be replaced by the fatty, in the various parts of the body, be as far as possible checked? We are taught that our only hope of cure of an aneurism lies in the possibility of filling its cavity with coagulated fibrine (a point upon which I propose to say something hereafter); but this result will never be bronght about by rendering the blood thin and watery.

This opinion, strongly put forward by Dr. Copland, has of late years been steadily gaining ground; and I cannot but think that depletion and lowering measures generally are not applicable to the majority of cases of aneurism, but are chiefly suitable in those cases which arise from sudden violence in persons in whom the aorta may reasonably be considered to be moderately free from disease, and in whom the body is robust and the circulation vigorous; or as a remedy for occasional vascular excitement in a few other cases. And if this view is correct, it is not sufficient merely to diagnose a case as one of aneurism; but before deciding on the treatment, it is necessary to go a step further, and determine, as far as possible, the exact condition of system out of which, or in which, the arterial disease has arisen.

Norwich, 1861.

\section{AN INQUIRY INTO A FREQUENT CAUSE OF INSANITY IN YOUNG MEN.}

\section{By ROBERT P. RITCHIE, M.D. EdIn., L.R.C.S.E., nYSIDENT PHYSICIAN OF BETHNAL IIOUSE ASYLUN.}

\section{PART I.}

ON entering an asylum for the insane, especially if it be one receiving patients from the middle as well as from the lower class of society, there is one group of inmates which may arrest the attention of the visitor from the contrast presented to the exoited persons around him, on the one hand, and to those who are convalescent on the other. Engaged in no social diversion, the patients of this group live alone in the midst of many. In their exercise, they choose the quietest and most unfrequented parts of the airing grounds. They join in no social conversa- tion, nor enter with others into any amusement. They walk alone, or they sit alone. If engaged in reading, they talk not to others of what they may have read; their desire apparently is, in the midst of numbers to be in solitude. They seek no social joys, nor is the wish for fellowship evinced.

In some asylums these patients form a considerable proportion of the male inmates; but, for reasons to be presently alluded to, it is not very remarkable that the cause of this kind of mental alienation, and its existence as a distinct form of disease, have by some been doubted. It is, however, remarkable that writers on mental maladies pass over this class of mental affection with scarcely an allusion to the occasion of it. It is surprising that those who undertake to treat of a whole subject should refer to so important a section in a most cursory and unsatisfactory manner. To this there are few exceptions. In Prichard's treatise, published in 1835, there is little or no information upon the sulject. With the exception of the late Sir W. Ellis, of Hanwell, there is scarcely an English author of a work on insanity who has entered upon it. In his "Treatise on Insanity," published in 1835, he specially alludes to this class of cases, and recognises its importance. He pertinently remarks: "A great deal has been said on dementia by previous writers on insanity, but this, the true cause of its origin in by far the greater number of cases, has not been mentioned."

Esquirol also allucles to patients of this class, but does not appear to have recognised that a regular and, I may say, constant set of symptoms indicate mental alienation proceeding from the cause treated of-the vice of masturbation. In his work "Des Maladies Mentales," in the chapter "De la Folie," (page 24, Brussels editiou, 1838,) it is written:- "La masturbation, ce fléan de l'espèce humaine, est plus souvent qu'on ne pense cause de folie, surtout chez les riches." Whilst at p. 35 he again writes:- "La masturbation, dont nous avons parlé sous un autre rapport, est signalée, dans tous les pays, comme une des causes fréquentes de folie; quelque fois est le prélude de la manie, de la démence, et même de la démence senile; elle jette dans la melancholie, conduit au suicide. Elle est plus funeste aux hommes qu'aux femmes," \&c.

In the excellent work lately presented to the public by Drs. Bucknill and Tuke, the design of which was to supply the want existing of a good treatise on insanity, solitary vice as a cause of mental disease has been all but passed over, and no available information upon this subject is afforded.

From the ages of antiquity the effect of indulgence in libidinous pleasures has been recognised, but their effect on the manifestation of the mind requires, it appears to me, further description. Some reliable information upon a matter so im. portant to the well-being of society cannot therefore be quite unnecessary. I am also induced to submit the following observations to the profession from the fact that in 119 cases which were recognised after admission into Bethnal House Asylum to be due to this melancholy canse, in only 6 was the true cause understood previous to admission; whilst the greater proportion of those cases in which the supposed cause was stated was attributed to religion or over-study.

Seeing, then, the necessity for more certain information, this communication is offered, in the hope that not only may the patient by timely aid be restored, but also that the general practitioner, when insanity has been thus produced, may be enabled to form some opinion as to the progress and results of the mental disease, and to warn the patient's friends of the uncertainty attending the progress of the malady. And who can doubt the importance of recognising these cases before the mental symptoms have become so uroent as to necessitate the interference of the alienist, when generally the physical system is so reduced, and the mind so impaired and shattered, that but little treatment of a sanative nature can be adopted?

Let us not ignore so powerful a cause of mental disease merely because it is a nameless vice, and one we blush even to allude to. It is of too frequent occurrence, and is too serious in its results, to be passed over lightly.

The inquiry into the mental characteristics and physical aspects of the lunatic victim, self-sacrificed to this vicious indulgence, will be best conducted by reviewing:-

I. Some of the statistics of the subject.

II. By inquiring into the mental phenomena and physical indications.

III. By our attention being directed to the prevention and treatment, both medical and moral.

\section{Stratistics.}

1. Frequency as a cause of insanity. - It is especially desirable to ascertain the frequency of cases of insanity arising from 